We thank Miss Eunice Berry and Miss Jean Taylor for secretarial help and the Wellcome Trust and Medical Research Council for financial support. Studies in Thailand were part of the WellcomeMahidol University-Oxford, Tropical Medicine Research Programme.

Requests for reprints should be addressed to: Dr D A Warrell, Faculty of Tropical Medicine, Mahidol University, 420/6 Rajvithi Road, Bangkok 10400, Thailand.

\section{References}

' Chang CC. The action of snake venoms on nerve and muscle. In: Lee C-Y, ed. Snake venoms. Berlin: Springer-Verlag, 1979:309-76.

2 Ahuja ML, Singh G. Snake bite in India. Indian 7 Med Res 1954;42: 661-86.

${ }^{3}$ Kuo T-P, Wu C-S. Clinico-pathological studies on snakebites in Taiwan The Snake 1972;4:1-22.

4 Smith MA. Fauna of British India Ceylon and Burma including the whole of the Indo-Chinese sub-region. Reptilia and Amphibia. Vol III. Serpentes. London: Taylor and Francis, 1943.

${ }^{5}$ Theakston RDG, Lloyd-Jones MJ, Reid HA. Micro-elisa for detecting and assaying venom and venom antibody. Lancet 1977;ii:639-41.

6 Warrell DA, Greenwood BM, Davidson NMcD, Ormerod LD, Prentice
CRM. Necrosis, haemorrhage and complement depletion following bites by the spitting cobra (Naja nigricollis). $Q \mathcal{F}$ Med $1976 ; 45: 1-22$. (D

7 Tilbury CR. Observations on the Mozambique spitting cobra (Naja mossambica mossambica). S Afr Med F 1982;61:308-13.

${ }^{8}$ Sethi PK, Rastogi JK. Neurological aspects of ophitoxemia (Indian krait? -a clinico-electromyographic study. Indian f Med Res 1981 ;73:269-76

${ }^{9}$ Richards V. Dr Fayrer's treatment of snake-bite by artificial respirationg Indian Medical Gazette 1873;8:118-20.

${ }^{10}$ Campbell $\mathrm{CH}$. Venomous snake bite in Papua and its treatment with tracheostomy, artificial respiration and antivenene. Trans $R$ Soc Trop Med Hyg 1964;58:263-73.

11 Reid HA. Diagnosis, prognosis and treatment of sea-snake bite. Lance 1961 ;ii :399-402.

12 Hood VL, Johnson JR. Acute renal failure with myoglobinuria after tige? snake bite. Med $\mathcal{F}$ Aust 1975;ii:638-41.

13 Chang CC. Studies on the mechanism of curare-like action of Bungarua multicinctus venom. I. Effect on the phrenic nerve-diaphragm prepara? tion of the rat. Fournal of the Formosan Medical Association 1960;59@ 315-23.

14 Banerjee RN, Sahni AL, Chacko KA. Neostigmine in the treatment of Elapidae bites. F Assoc Physicians India 1972;20:503-9.

${ }^{15}$ Ramakrishnan MR, Sankaran K, Gupta GD, Chandrasekar S. External. ophthalmoplegia in Elapidae bites and its response to neostigmine $\vec{\omega}$ Neurology India 1975;23:109-10.

(Accepted 24 December 1982)

\title{
Intramuscular on demand analgesia: double blind controlled trial of pethidine, buprenorphine, morphine, and meptazinol
}

\author{
M HARMER, P J SLATTERY, M ROSEN, M D VICKERS
}

\begin{abstract}
An on demand intramuscular analgesic system using the Cardiff Palliator was tested. Forty consenting patients were studied after cholecystectomy in a double blind trial using increments of buprenorphine (0.15 $\mathrm{mg})$, meptazinol $(50 \mathrm{mg})$, morphine $(5 \mathrm{mg})$, and pethidine $(50 \mathrm{mg})$. Most patients attained good levels of pain relief (mean analogue pain score 36.5 ), comparable to intravenous on demand analgesia. There were no technical complications. Significant differences were found between drugs in dizziness (pethidine produced the worst score) but not with other side effects. Buprenorphine produced longer lasting analgesia than meptazinol or pethidine and also gave the lowest pain scores. Patterns of analgesic consumption were the same as with intravenous on demand systems, but larger amounts of drug were generally used. Relative analgesic potencies derived from drug consumption rates were also consistent with those from intravenous on demand studies.

An on demand intramuscular analgesic system offers a simple but effective means of relieving severe postoperative pain.
\end{abstract}

\section{Introduction}

Routine intermittent intramuscular injections of analgesic administered by nurses do not give good postoperative analgesia $\stackrel{\mathbb{Q}}{2}$ and many other methods of administration have been claimed to give better results. ${ }^{2-6}$ Studies on any novel system for dispensing analgesics are apt to yield better results than existing practice by increasing the attention paid to individual patients. The value. of any innovation will, however, also depend on implementatios and practicality for routine use.

A system combining the simplicity (and acceptability to nursing staff) of intramuscular injections together with the versatility (and intuitive appeal to patients) of an on demanis system would seem to have practical advantages.

An initial pilot study showed that repeated injections througd an indwelling intramuscular cannula produced little or n\& discomfort so long as the volume and rate of injection wer? limited. This study was performed to determine whether a intramuscular on demand system would give good postoperative pain relief without introducing further problems. As the effectiveness of intramuscular analgesics may be influenced bow physicochemical factors affecting rate of absorption, fou里 different drugs (buprenorphine, meptazinol, morphine, and pethidine) were studied. Morphine and pethidine have been̄ used in most methods of pain relief so far described; buprenor? phine and meptazinol have been studied in intravenous op demand systems. ${ }^{78}$

\section{Methods}

Forty patients undergoing uncomplicated elective cholecystectom were studied; they were aged between 18 and 70 years, and none of the women was pregnant. The trial was conducted double blin patients being allocated at random to receive one of the analgesics for 
24 hours after operation. The random allocation and preparation of drugs was performed independently.

Each patient was visited the day before operation to obtain informed consent and instructed in the use of the apparatus. They were also introduced to the concept of the linear analogue, ${ }^{9}$ which was used to record the intensity of pain and other symptoms.

The patients were premedicated with diazepam (roughly $0.15 \mathrm{mg} / \mathrm{kg}$ ) administered by mouth one to two hours before operation. Anaesthesia was induced with intravenous thiopentone $(3-4 \mathrm{mg} / \mathrm{kg})$, tracheal intubation facilitated with suxamethonium or a non-depolarising relaxant, and the patients ventilated with nitrous oxide, oxygen, and halothane supplemented with up to $0.2 \mathrm{mg}$ intravenous fentanyl. At the end of the operation residual neuromuscular blockade was reversed with atropine and neostigmine.

While the patient was recovering from anaesthesia a fine Teflon intravenous cannula (Wallace 24 gauge) was inserted into the deltoid muscle of the non-dominant arm. The cannula was connected by low volume manometer tubing and bacterial filter to the syringe containing the analgesic solution. The injection site was sprayed with povidoneiodine and covered with a transparent occlusive dressing. The analgesic was administered by a patient controlled syringe pump, ${ }^{10}$ available as the Cardiff Palliator. This apparatus was set to deliver an incremental dose of $0.5 \mathrm{ml}$ analgesic solution over five minutes with a minimum interval of 20 minutes between demands. The concentrations used were pethidine $100 \mathrm{~g} / \mathrm{l}$, buprenorphine $300 \mathrm{mg} / \mathrm{l}$, morphine $10 \mathrm{~g} / \mathrm{l}$, and meptazinol $100 \mathrm{~g} / 1$.

On first requesting analgesia the patient was given the demand control and reminded how to use it. While in the recovery ward the first interval limit of 20 minutes was overidden on most occasions so that an adequate initial degree of analgesia could be attained. Patients were kept in the recovery ward until proficient in the use of the device and then returned to the surgical ward. Standard records of arterial blood pressure and heart and respiratory rates were completed by the ward staff. Any patient who complained of nausea or vomited was given intramuscular metoclopramide $10 \mathrm{mg}$. An alternative intermittent intramuscular analgesic regimen was prescribed for use in the event of rejection of the on demand system.

TABLE I-Details of patient

\begin{tabular}{lllccc}
\hline & $\begin{array}{c}\text { Mean } \\
\text { age }-S D \\
(\text { years })\end{array}$ & $\begin{array}{c}\text { Mean } \\
\text { weight } \\
(\mathrm{kg})\end{array}$ & $\begin{array}{c}\text { No of } \\
\text { women } \\
\text { in group }\end{array}$ & $\begin{array}{c}\text { No given } \\
\text { intra- } \\
\text { operative } \\
\text { analgesia }\end{array}$ & $\begin{array}{c}\text { Noceiving } \\
\text { post- } \\
\text { operative } \\
\text { antiemetics }\end{array}$ \\
\hline $\begin{array}{c}\text { Buprenorphine } \\
(\mathrm{n}=10)\end{array}$ & $47 \cdot 1 \div 13 \cdot 5$ & $64 \cdot 8 \pm 16 \cdot 4$ & 8 & 5 & 4 \\
$\begin{array}{c}\text { Meptazinol } \\
(\mathrm{n}=9)^{*}\end{array}$ & $41 \cdot 7 \pm 12 \cdot 4$ & $69 \cdot 9 \pm 9 \cdot 4$ & 7 & 4 & 7 \\
$\begin{array}{c}\text { Morphine } \\
(\mathrm{n}=10)\end{array}$ & $49 \cdot 8 \pm 12 \cdot 2$ & $68 \cdot 2 \pm 14 \cdot 9$ & 5 & 7 & 5 \\
$\begin{array}{c}\text { Pethidine } \\
(\mathrm{n}=10)\end{array}$ & $42 \cdot 7 \div 12 \cdot 4$ & $71 \cdot 5 \pm 13 \cdot 4$ & 7 & 5 & 2 \\
\hline
\end{tabular}

* One patient withdrawn from trial after four hours as unable to achieve satisfactory analgesia with meptazinol.
Between two and four hours after operation the patients were assessed for conscious state and questioned about pain and nausea (these assessments being scored on a 1-5 scale of degree). They were also asked about pain at the injection site, which was inspected for redness or swelling. At this visit any sweating, pallor, wincing, and retching were noted.

About 24 hours after operation patients were asked to mark linear analogues representing pain, dizziness, drowsiness, and nausea, reflecting average degree of discomfort over the 24 hours. They were also questioned directly about abdominal pain, unpleasant dreams, and discomfort at the injection site. The incidence of administration of an antiemetic was also recorded. The cannula was then removed and the patient prescribed a standard analgesic to be given intramuscularly if required.

Three or four days after operation the injection site was again inspected and the interval between removal of the on demand infusion and administration of the prescribed standard analgesic noted.

Statistical analysis of differences between groups was by parametric and non-parametric (Kruskal-Wallis) analysis of variance techniques and $\chi^{2}$ and Mann-Whitney $U$ tests, as appropriate.

\section{Results}

Details of patients (table I)-There were no statistically significant differences among the four groups of patients with respect to age, weight, sex distribution, or incidence of peroperative analgesic administration.

Amounts of analgesic taken (table II)-There was considerable individual variation in consumption. The average amount of analgesic demanded by each group exceeded that which would routinely be prescribed for administration by nursing staff. There was, however, no evidence of overdose-that is, a depressed conscious state or a respiratory rate less than $10 / \mathrm{min}$. Analgesic equipotencies derived from 24 hour consumptions were pethidine $100 \mathrm{mg}$, meptazinol 139 $\mathrm{mg}$, morphine $8.6 \mathrm{mg}$, and buprenorphine $0.26 \mathrm{mg}$.

Rate of analgesic consumption-All four groups showed an initial high rate of demand which fell to a steady level after six hours. The mean consumption rates $(\mu \mathrm{g} / \mathrm{kg} / \mathrm{h})$ for the first six hours and the remainder of the 24 hour period were $2 \cdot 81$ and $1 \cdot 17,1312$ and 675 , $84 \cdot 3$ and $40 \cdot 7$, and 769 and 524 for buprenorphine, meptazinol, morphine, and pethidine respectively.

Analgesia and side effects (table III)-Between two and four hours after operation the conscious level was assessed and sweating, pallor, retching, or wincing noted as well as any pain or swelling at the injection site. Patients were also questioned directly about pain and nausea. These assessment scores (table III) showed no significant differences among the groups of patients. The linear analogue scores for dizziness and nausea showed a non-normal distribution, and table IV therefore gives these as median and range. Differences between drugs were tested by non-parametric analysis of variance. The pain scores showed considerable differences between groups which approached significance $(0 \cdot 1>p>0.05)$. Buprenorphine produced the lowest and pethidine the highest scores. The dizziness scores were

\begin{tabular}{|c|c|c|c|c|c|}
\hline & \multicolumn{4}{|c|}{ Treatment } & \multirow{2}{*}{ Statistical } \\
\hline & $\begin{array}{c}\text { Buprenorphine } \\
(\mathrm{n}=10)\end{array}$ & $\underset{(\mathrm{n}=9)}{\text { Meptazinol }}$ & $\begin{array}{c}\text { Morphine } \\
(\mathrm{n}=10)\end{array}$ & $\begin{array}{l}\text { Pethidine } \\
(\mathrm{n}=10)\end{array}$ & \\
\hline $\begin{array}{l}\text { Mean No of demands in } 24 \text { hours (range) } \\
\text { Mean dose }(\mathrm{mg}) \text { taken in } 24 \text { hours (range) } \\
\text { Mean dose }(\mathrm{mg} / \mathrm{kg} / 24 \mathrm{~h}) \\
\text { Median duration (h) of effect* (range) }\end{array}$ & $\begin{array}{c}16(4-23) \\
2 \cdot 5(0 \cdot 6-3 \cdot 5) \\
0 \cdot 039 \\
10 \cdot 6(6 \cdot 6-+)\end{array}$ & $\begin{array}{c}28(16-37) \\
1394(800-1850) \\
20 \cdot 41 \\
5 \cdot 3(0 \cdot 9-8 \cdot 7)\end{array}$ & $\begin{array}{c}17(10-26) \\
87(50-130) \\
1 \cdot 27 \\
8 \cdot 2(2 \cdot 4-30 \cdot 1)\end{array}$ & $\begin{array}{c}20(7-29) \\
1010(350-1450) \\
14 \cdot 74 \\
3.9(1 \cdot 8-11 \cdot 0)\end{array}$ & $\chi^{2}=10.93 ; \mathrm{df}=3 ; 0.025>p>0.01 \ddagger$ \\
\hline
\end{tabular}

*Interval between end of intramuscular on demand infusion and first subsequent staff administered analgesic.

${ }_{\dagger}^{+}$Tested by Kruskal-Wallis one way analysis of variance by ranks.

TABLE III-Results of assessment two to four hours after operation

\begin{tabular}{|c|c|c|c|c|c|c|c|c|c|c|}
\hline & \multirow[b]{2}{*}{ Sweating } & \multicolumn{2}{|c|}{ No of positive observations } & \multirow[b]{2}{*}{ Wincing } & \multicolumn{2}{|c|}{ Drowsiness* } & \multicolumn{2}{|c|}{ Pain* } & \multicolumn{2}{|c|}{ Nausea* } \\
\hline & & Pallor & Retching & & Scores $<3$ & Scores $\geqslant 3$ & Scores $<3$ & Scores $\geqslant 3$ & Scores $<3$ & Scores $\geqslant 3$ \\
\hline $\begin{array}{l}\text { Buprenorphine }(n=10) \\
\text { Meptazinol }(n=10) \\
\text { Morphine }(n=10) \\
\text { Pethidine }(n=10)\end{array}$ & $\begin{array}{l}1 \\
1 \\
1 \\
1\end{array}$ & $\begin{array}{l}4 \\
6 \\
4 \\
4\end{array}$ & $\begin{array}{l}0 \\
1 \\
1 \\
0\end{array}$ & $\begin{array}{l}0 \\
1 \\
2 \\
2\end{array}$ & $\begin{array}{l}8 \\
7 \\
5 \\
6\end{array}$ & $\begin{array}{l}2 \\
3 \\
5 \\
4\end{array}$ & $\begin{array}{l}7 \\
2 \\
4 \\
4\end{array}$ & $\begin{array}{l}3 \\
8 \\
6 \\
6\end{array}$ & $\begin{array}{l}8 \\
8 \\
9 \\
9\end{array}$ & $\begin{array}{l}2 \\
2 \\
1 \\
1\end{array}$ \\
\hline
\end{tabular}

*These symptoms assessed on 1-5 ordinal scale of increasing severity. 
TABLE IV-Linear analogue results. * Figures are medians (range)

\begin{tabular}{|c|c|c|c|c|}
\hline Treatment & Pain & Drowsiness & Dizziness & Nausea \\
\hline \multirow{4}{*}{$\begin{array}{l}\text { Buprenorphine } \\
(\mathrm{n}=10) \\
\text { Meptazinol } \\
(\mathrm{n}=9) \\
\text { Morphine } \\
(\mathrm{n}=10) \\
\text { Pethidine } \\
(\mathrm{n}=10)\end{array}$} & $24 \cdot 0(0-40)$ & $76.5(49-98)$ & $7 \cdot 0(0-38)$ & $12.5(0-97)$ \\
\hline & $38.0(5-64)$ & $75 \cdot 0(37-98)$ & $1 \cdot 0(0-65)$ & $28.0(10-99)$ \\
\hline & $31 \cdot 5(6-93)$ & $74 \cdot 5$ (20-97) & $13.0(0-93)$ & $28.5(6-85)$ \\
\hline & $52 \cdot 0(10-67)$ & $82 \cdot 5(52-99)$ & $33.0(3-77)$ & $11.5(0-45)$ \\
\hline $\begin{array}{l}\text { Treatment } \\
\text { differencet } \\
\left(x^{2} ; \mathrm{df}=3\right)\end{array}$ & $\begin{array}{c}6.82 \\
(0.1>p>0.05)\end{array}$ & $\begin{array}{c}2 \cdot 87 \\
(p>0 \cdot 1)\end{array}$ & $\begin{array}{c}9.31 \\
(0.05>p>0.025)\end{array}$ & $\begin{array}{c}6 \cdot 04 \\
(p>0 \cdot 1)\end{array}$ \\
\hline
\end{tabular}

*Scales 0-100 (low score advantageous).

+ Tested by Kruskal-Wallis one way analysis of variance by ranks.

significantly different $(0.05>p>0.025)$, pethidine having the worst score. There were no significant differences among the drugs in degree of nausea or drowsiness.

Injection site-On examination after 24 hours localised swelling or induration was noted in nine of the 40 patients, and two reported pain or discomfort at the site at some time. When examined between three and five days later swelling or induration was still present locally in eight patients, and four reported some pain or discomfort at the site over the previous days. Localised redness which persisted for several days was noted in one patient at the time.

Duration of action of drugs-The interval between removal of the on demand system and the patient's next request for analgesic was used to estimate duration of drug effect (table II). Testing by nonparametric analysis of variance showed significant $(p<0.025)$ differences among the drugs; buprenorphine produced the longest median duration of effect and pethidine the shortest.

\section{Discussion}

The intramuscular on demand system worked well and produced effective analgesia in most patients (mean analogue pain score 36.5 ); the pain scores were similar to those reported after intravenous on demand analgesia. ${ }^{8-11}$ The high analgesic consumption in the first hours after operation and the extreme variation among patients in analgesic requirement (up to sixfold for buprenorphine) were consistent with previous findings for self administration schemes and show the flexibility of on demand systems in meeting individual requirements. One patient failed to achieve satisfactory analgesia in the initial hours after operation, but when morphine was substituted for the test drug (meptazinol) good analgesia was attained. In subsequent hours this patient consumed more drug than average in the morphine group but less than the highest recorded.

Meptazinol is a relatively new agonist-antagonist analgesic, which in intravenous on demand ${ }^{8}$ and other studies ${ }^{12}$ reportedly produced a high incidence of nausea and vomiting; it did not, however, produce significantly higher nausea scores than other drugs in this study. The rate of consumption of meptazinol confirms previous observations that in these terms it is less potent than pethidine, although it seems relatively more effective when given intramuscularly than intravenously. ${ }^{8}$

Pethidine produced less satisfactory results than buprenorphine, both in quality of analgesia and in duration of effect. This is consistent with reports of relatively high efficacy of buprenorphine administered intramuscularly ${ }^{13}$ and extremely variable absorption of pethidine after intramuscular injection. ${ }^{14}$ These observations, together with the side effects associated with pethidine, suggest that buprenorphine would be the better drug for use in this system.

Interestingly the relatively higher consumption of pethidine and buprenorphine in this study did not produce better relief of pain than when the same drugs were taken intravenously under the same conditions. ${ }^{811}$ This may be due to altered rates of elimination or to local effects at the site of infusion. Although the interval elapsing between removal of the on demand apparatus and the first subsequent administration of analgesic by the nursing staff demonstrates differences among the analgesics with regard to duration of action, it shows no firm evidence of $\stackrel{\AA}{\varrho}$ prolonged release from the infusion site.

This administration system was tolerated very well by the $\widehat{\widehat{\Omega}}$ patients and no spontaneous comments or complaints about pain or discomfort were made. The incidence of local complications $\mathbb{\Phi}_{\mathbb{D}}$ with respect to pain and erythema was not greatly different ${ }^{\infty}$ from that reported for insertion of an intravenous cannula and $\frac{\mathrm{m}}{2}$ two injections of saline solution. ${ }^{15}$

An intramuscular on demand infusion requires little skill to $\overrightarrow{\overrightarrow{\mathrm{s}}}$ implement and may be an attractive alternative in a non-special- $\overrightarrow{0}$ ised medical environment. Though our patients showed no $\frac{E}{\partial}$ evidence of undesirable side effects, respiratory changes have $\overline{\overline{\bar{D}}}$ been reported with both on demand ${ }^{16}$ and continuous infusion ${ }^{17} \widehat{\Phi}$ analgesic systems and frequent observation of the patient must be advised.

\section{References}

1 Cronin M, Redfern PA, Utting JE. Psychometry and postoperative

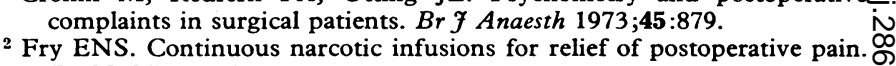
Br Med 7 1979; i: 1149 .

3 Davenport HT, Wright BM. Relief of postoperative pain. Br Med $\mathcal{F}$ $1979 ; 1: 1561$.

4 Church JJ. Continuous narcotic infusions for relief of postoperative pain. Br Med f 1979 ;i:977. ${ }^{5}$ Sechzer PH. Studies in pain. Anesthesia and Analgesia: Current Research ${ }^{\circ}$

${ }^{6}$ Slattery PJ, Harmer M, Rosen M, Vickers MD. An open comparison $N$ between routine and self-administered postoperative pain relief. Ann $R$ Coll Surg Engl (in press).

7 Chakravarty K, Tucker W, Rosen M, Vickers MD. Comparison of buprenorphine and pethidine given intravenously on demand to relieve postoperative pain. $\mathrm{Br} \mathrm{Med} \mathcal{F} 1979$;ii:895.

${ }^{8}$ Slattery PJ, Harmer M, Rosen M, Vickers MD. Intravenous meptazinol for postoperative analgesia. Br f Anaesth 1981;53:927.

${ }^{9}$ Revili SI, Robinson JO, Rosen M, Hogg MIJ. The reliability of a lineare analogue for evaluating pain. Anaesthesia 1976;31:1191.

10 Evans JM, Rosen M, MacCarthy J, Hogg MIJ. Apparatus for patient controlled administration of intravenous narcotics during labour. Lancet $1976 ; \mathrm{i}: 17$.

1 Harmer M, Slattery PJ, Rosen M, Vickers MD. Buprenorphine and pentazocine used on demand for postoperative analgesia. $\mathrm{Br} \mathcal{F}$ Anaesth (in press).

12 Gibbs JM, Johnson HD. A trial of meptazinol for the relief of pain after abdominal surgery. Anaesth Intensive Care 1980;8:441.

${ }^{13}$ McQuay HJ, Bullingham RES, Paterson GMC, Moore RA. Clinical effects of buprenorphine during and after operation. BrF Anaesth 1980 ; 52:1013.

1 Austin KL, Stapleton JV, Mather LE. Multiple intramuscular injections. A major source of variability in analgesic response to meperidine. Pain $1980 ; 8: 47$.

${ }^{15}$ Mikkelson H, Hoel TM, Bryne H, Krohn CD. Local reactions after IV injections of diazepam, flunitrazepam and isotonic saline. $\mathrm{Br} \mathcal{F}$ Anaesth 3 $1980 ; 52: 817$.

16 Gibbs JM, Johnson HD, Davis FM. Patient administration of IV buprenorphine for postoperative pain relief using the "Cardiff" demand analgesia apparatus. $B r \mathcal{F}$ Anaesth 1982;54:279.

17 Catling JA, Pinto DM, Jordan C, Jones JG. Respiratory effects of analgesia after cholecystectomy: comparison of continuous and intermittent papaveretum. Br Med f 1980;281:478.

(Accepted 17 December 1982)

HEART TREFOIL. Besides the ordinary sort of Trefoil, here are two mores remarkable, and one of which may be properly called Heart Trefoil, not only because the leaf is triangular, like the heart of a man, but also because each leaf contains the perfection of a heart, and that in its proper colour, viz a flesh colour. It grows between Longford and $\frac{\widehat{D}}{\mathbb{D}}$ Bow, and beyond Southwark, by the highway and parts adjacent.

It is under the dominion of the Sun, and if it were used, it would be found as great a strengthener of the heart, and cherisher of the vital spirits as grows, relieving the body against fainting and swoonings fortifying it against poison and pestilence, defending the heart against the noisome vapours of the spleen. (Nicholas Culpeper (1616 $\frac{6}{2}$ 54) The Complete Herbal, 1850.) 